RHINOLOGY

\title{
The hump columellar strut: a reliable technique for correction of nasal tip underprojection
}

\author{
Lo strut columellare ricavato dal gibbo nasale: una tecnica affidabile \\ per la correzione di deficit di proiezione della punta
}

\author{
P.G. GIACOMINI', S. MOCELLA², S. DI GIROLAMO'1, R. DE BERARDINIS ${ }^{1}$, A. BOCCIER|3 \\ ${ }_{1}^{1}$ Department of Otorhinolaryngology, Tor Vergata University, Rome, Italy; ${ }^{2}$ Department of Otorhinolaryngology, \\ Bussolengo Hospital “Orlandi”, Verona, Italy; ${ }^{3}$ Department of Maxillo-Facial Surgery, S. Camillo Hospital, Rome, \\ Italy
}

\section{SUMMARY}

Nasal tip under projection is often found in rhinoplasty cases both for congenital or post-traumatic deformity. Nasal trauma may result in alteration of the external and internal nasal structures with following aesthetic impairment and difficulties in breathing. Post-traumatic surgery is frequent, but restoration of pre-traumatic form and function remains a challenge. The present paper describes a new method to increase tip projection by a columellar strut harvested from the autologous nasal bone and cartilage of the resected hump. A total of 15 cases ( 11 women/4 men, mean age $32.6 \pm 12.3$ years) of major tip projection/misalignment abnormalities to be corrected by increased nasal tip projection were drawn, and all underwent closed or open rhinoplasty with the placement of a bony columellar strut harvested from the resected hump of the patient. Short and long-term advantages of this procedure are to be underlined. Harvesting is routinely performed during dorsal resection and preparation of the graft is easy. Differently from bone of the vomer or the inferior turbinate, this is cortical bone straight in shape and rigid in framework, and therefore ideal to gain reliable tip support overtime. No additional harvesting areas are needed. Placement of this bony strut is carried out in the standard fashion without additional dissection or further procedures. Long-term follow-up shows maintained projection over time. This graft can be combined with various grafting or suturing techniques usually applied according to each surgeon's experience and the needs of each patient.

KEY WORDS: Columellar strut • Nasal hump • Bony graft

\section{RIASSUNTO}

Molti casi di alterazioni della proiezione della punta nasale, sia per deformità congentita che post-traumatica, sono trattati con intervento chirurgico di rinoplastica. Un trauma nasale può causare alterazioni delle strutture nasali esterne e interne con conseguente compromissione estetica e difficoltà respiratoria. Spesso si tratta di una chirurgia post-traumatica, ma il recupero della forma prima del trauma e della funzione rimane tuttora una sfida. Tale studio ha lo scopo di descrivere un nuovo metodo con il quale trattare deficit di proiezione della punta tramite uno strut columellare proveniente da osso nasale autologo e cartilagine del gibbo asportato. Sono stati esaminati 15 casi (11 donne/4 uomini, età media 32,6 \pm 12,3 anni) con gravi anomalie della proiezione/disallineamento della punta, $i$ quali sono stati sottoposti a rinoplastica chiusa o aperta e con posizionamento di uno strut columellare osseo raccolto dal gibbo resecato dal paziente stesso. Sono stati ottenuti risultati a breve e a lungo termine. Durante la resezione dorsale, la raccolta dell'innesto viene fatta di routine. A differenza dell'osso del vomere e dei turbinati inferiori, tale osso corticale è dritto e rigido ed è, quindi, ideale per ottenere un supporto utile alla punta. Non sono, pertanto, necessarie altre preparazioni di innesti. Il posizionamento dello strut osseo avviene in maniera standardizzata senza dissezione supplementare o ulteriori procedure. Tale trapianto può essere combinato con varie tecniche di innesto o di sutura solitamente in base all'esperienza di ciascun chirurgo e in base alle esigenze di ogni singolo caso.

PAROLE CHIAVE: Strut columellare • Gibbo nasale • Trapianto osseo

Acta Otorhinolaryngol Ital 2018;38:45-50

\section{Introduction}

Nasal tip under projection is often found in rhinoplasty cases both for congenital or post-traumatic deformity.
Nasal trauma may result in alteration of the external and internal nasal structures with subsequent aesthetic impairment and difficulties in breathing. Post-traumatic surgery is frequent, but restoration of pre-traumatic form and 
function remains a challenge ${ }^{12}$. Recurrence is very common because of cartilage memory and scar contracture so that permanent support is needed to prevent relapse and maintain the correction over time. Various kinds of structural grafts have been proposed in order to reinforce/replace the traumatised or missing structures ${ }^{34}$.

Specifically, in the case of under projected and ptosis tip often medial crura support is reduced and real or pseudohump of the dorsum is part of the deformity. These alterations are frequently combined with weak and distorted nasal septum. Columellar strut grafting is required in these cases to gain re-positioning of the tip, but the availability of grafting material from the septum may be jeopardised by the above-mentioned deformities.

Options to recruit additional material include autologous cartilage/bone from the auricle, rib, calvarium, or iliac crest $^{5-11}$, or alloplastic implants e.g. high-density polyethylene, silicone etc. ${ }^{12-15}$. A neglected source of autologous grafting material lies within the operative field and obviates the need for a second operative graft harvesting site: the resected dorsal hump ${ }^{3}$.

The resected hump may be trimmed to harvest bone tissue to be fashioned and placed properly as columella strut with no added patient morbidity to provide nasal tip realignment and support. Our experience and long-term follow-up of functional and aesthetic results of this technique are reported.

\section{Materials and methods}

A total of 265 unselected, consecutive primary rhinoplasties treated from January 2007 to December 2012 were retrospectively analysed. A Goode ratio less than 0.55 was considered as a feature of hypo-projected tips, while a normal nasal tip projection was defined ranging from 0.55 to $0.61^{16}$.

15 cases ( 11 women, 4 men; mean age $32.6 \pm 12.3$ years) of major tip projection/misalignment abnormalities to be corrected by increased nasal tip projection were drawn, and all underwent closed or open rhinoplasty with the placement of a bony columellar strut harvested from the resected hump of the patient. Five patients were also given an unilateral spreader graft made from the same bone for re-alignment of the caudal-dorsal septum. A minimal two years follow-up available was considered as selection criteria.

A closed approach with alar cartilage delivery exposure and sub-periosteal hump resection through intercartilaginous and transfix incisions was used in 10 cases. An open approach with inverted $\mathrm{V}$ columellar incision was preferred in 5 cases with severe tip deformities. Hump removal was always performed by using a \# 10 and 12 Rubin osteotome. Standard septoplasty was always carried out with minimal resection of the quadrangular cartilage and conservative repositioning of the vomer bone. Tip shape and projection were then addressed by cephalic resection of the lower lateral cartilage with interdomal suturing.

The hump columellar strut was trimmed from the nasal bone using a Mayo scissor: the cephalocaudal dimension equalling the high of the existing medial crura (Fig. 1). Excessive thickness of the hump was corrected by drilling to obtain a flat graft. The cartilaginous part of the hump was left attached to the bone graft and trimmed according to the individual needs. To avoid risks of fracture while driving a curved needle through the implant, one or two preliminary holes are developed by a straight cutting needle or $2 \mathrm{~mm}$ round burr (Fig. 2). The next step is the placement between the medial crura (Fig. 3) and fixation of the strut to the medial crura using one trough-and-trough 4-0 polyglactin or polydioxanone suture. Two mattress stiches run in the inferior and superior membranous septum to prevent posterior dislodging and upward rotation of the columellar complex. An additional one or two stabilising sutures can be placed between the cartilaginous septum and the caudal margin of the medial crura.

In cases of osteocartilaginous hump graft, the bony portion is placed towards the nasal spine and the cartilage is put between the dome in order to have better flexibility of the tip. Moreover, suturing of the strut to the medial crura is easier and the stiffness of the tip is reduced.

Should additional projection be required, a tip cartilaginous onlay graft in a T fashion may be placed. The nose is taped and cast in standard fashion. Packing $(3 \times 18$-inch petroleum-impregnated gauze for 48 hours) is not mandatory, but was used in case of concomitant turbinate surgery.

Oral and written informed consent for participation in this study was obtained from each subject.

The follow-up ranged from 12 to 60 months (mean: 12 months).

Preoperative and postoperative photographs were taken with a digital camera with flash lighting, postoperative subjective satisfaction (surgeons) was measured by visuo-analogue scale (scores 0-5). Post-operative patient satisfaction was measured by the Roe Validated Questionnaire ${ }^{17}$.

Comparisons were made of the change in the tip position with regards to lateral deviation and upward rotation. Photo documentation and measurements of nasal tip projection using the Goode ratio were obtained at least 12 months after surgery.

Evaluations were carried out by a physician uninvolved in patient care to avoid possible bias. Statistical evaluation 


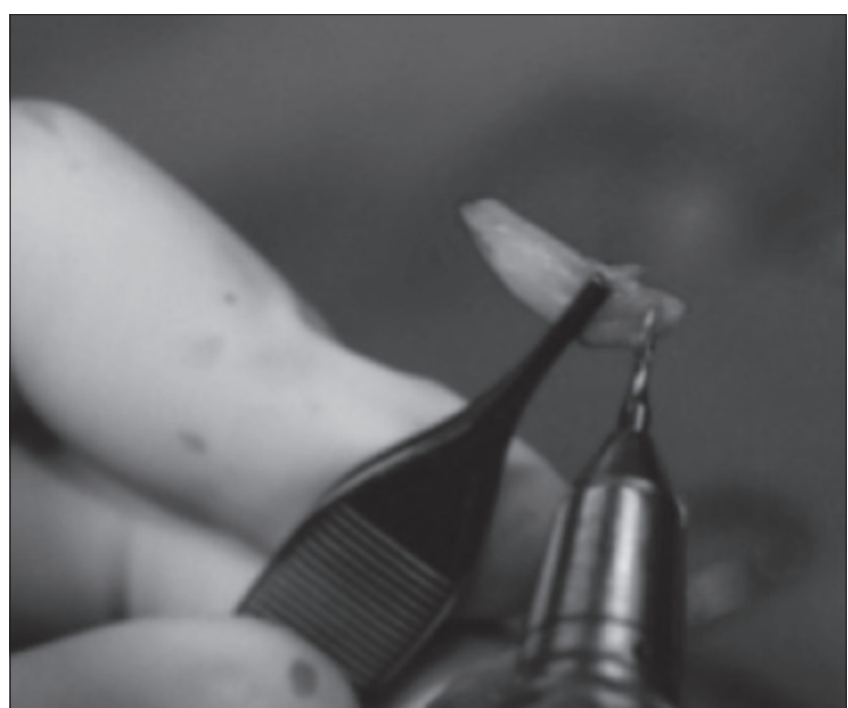

Fig. 1. Hump Graft shaped.

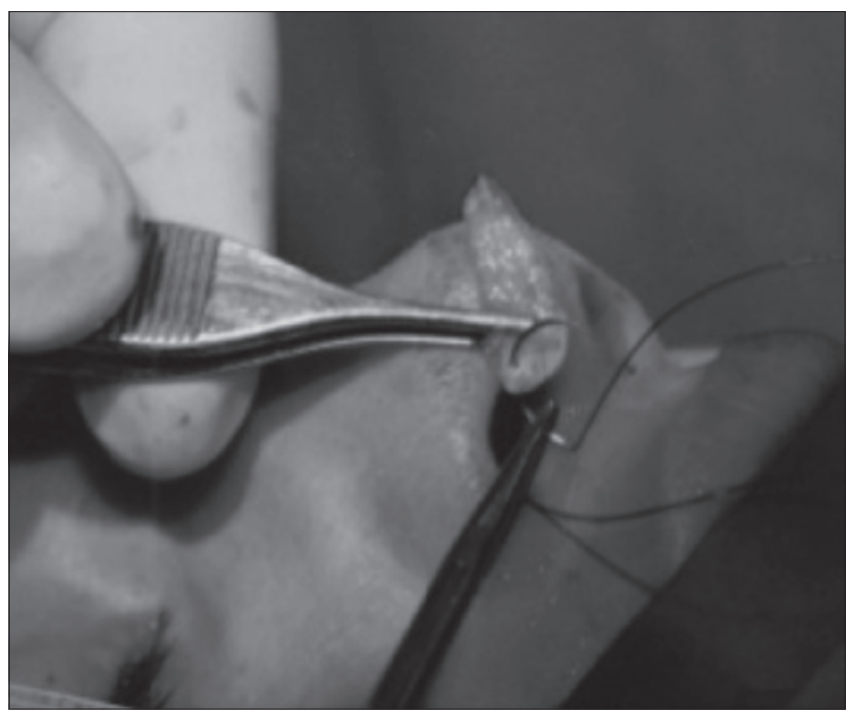

Fig. 2. Graft carving.

was carried out by computer-assisted (Microsoft-Excel. USA) mean + SD comparisons by 2-tail/paired data Student's T-test $(\mathrm{p}<0.05)$.

\section{Results}

In all patients tip projection improvement was gained and demonstrated by means of visual (Fig. 3) and Goode ratio analysis (Table I). Follow-up showed maintained result overtime. No graft reabsorption (Fig. 4), infection or extrusion were observed and no other complications were recorded in this series.

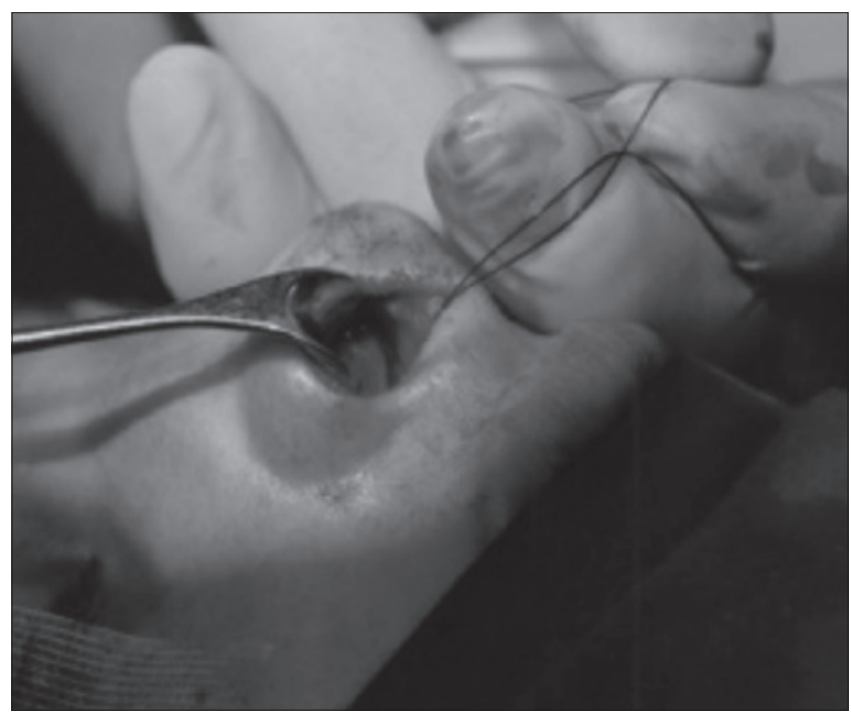

Fig. 3. Graft positioning.

The alar cartilage misdirection observed preoperatively in 6 patients $(40 \%)$ was corrected without recurrence overtime. In $2(13 \%)$ more patients with absence of the caudal septum, the columellar retraction was significantly improved by using this this type of graft.

Surgeon's judgment of results ranked an overall 3.1 score. Patient's aesthetic judgment of his/her nose improved markedly at Roe Self Valuation (Table II).

Adjunctive revisions or refinements of the first operation were needed in 1 case (6\%) of under-projecting tip; cause of revision was tip asymmetry not linked to the graft, but to the outcome of suturing.

Two typical cases are shown in Figures 4 and 5. Correction of tip under projection was performed using the hump bone graft columellar strut technique.

\section{Discussion}

The modification of the projection of nasal tip requires a thorough understanding of the anatomy and physiology of its components. The framework is made by the alar cartilages that act as a tripod based on medial and lateral crura: muscles and gliding areas allow the movements of the rigid structures loosely inter-connected. The biodynamics of this functional unit have been reviewed by focusing on

Table I. Measures of tip projection improvement by and Goode ratio analysis.

\begin{tabular}{lc} 
Measurement & Mean ratio \\
Pre-operative & $0.50 \pm 0.25$ \\
Post-operative 3 months & $0.58 \pm 0.12$ \\
Post-operative 12 months & $0.57 \pm 0.15$ \\
\hline
\end{tabular}




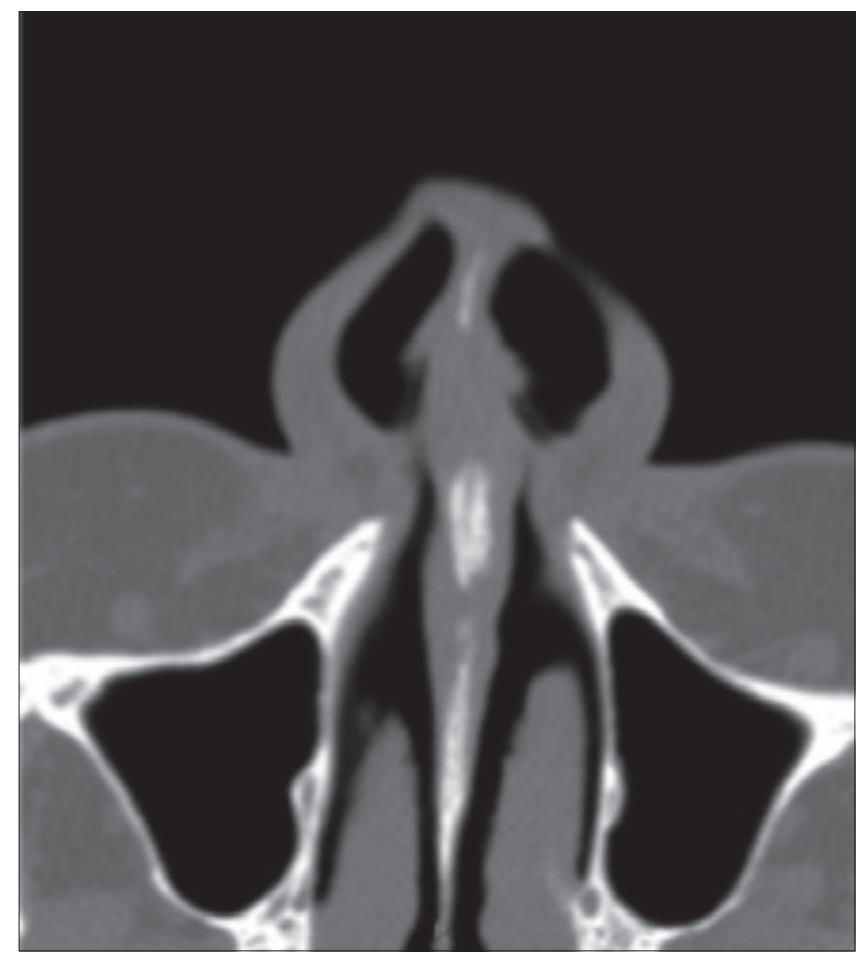

Fig. 4. CT scan: graft in place at 5 years follow-up.

the importance of length, thickness and resistance of the alar cartilage on determination of nasal tip projection ${ }^{18-20}$. It must be underlined that a correct morphological-functional result may be obtained with the re-shaping of the tip framework with careful respect of the alar muscular and ligament structures that allow the alar cartilages to act as a dynamic "spring" that keeps the nasal valve patent. Specifically, we feel that the relationship between lateral and medial crura length is a key point that must be evaluated and corrected to obtain the desired result. Additionally, the shape of the dome may influence the medial/lateral crura length ratio, thus influencing both tip projection and shape. It follows that a sound surgical correction must recreate the right proportions of these cartilages as well as a physiological function of the same. An important aspect seen in long-term follow-up of a consistent series of cases treated is the importance of maintaining or re-enforce the medial crura-caudal end of the septum relationship to support the tip projection. Our initial enthusiasm for alar car-

Table II. Roe patient satisfaction evaluation.

\begin{tabular}{lc} 
Measurement & Mean ratio \\
Pre-operative & $26.5 \pm 9.1$ \\
Post-operative 3 months & $78.1 \pm 12.3$ \\
Post-operative 12 months & $78.5 \pm 10.1$ \\
\hline
\end{tabular}

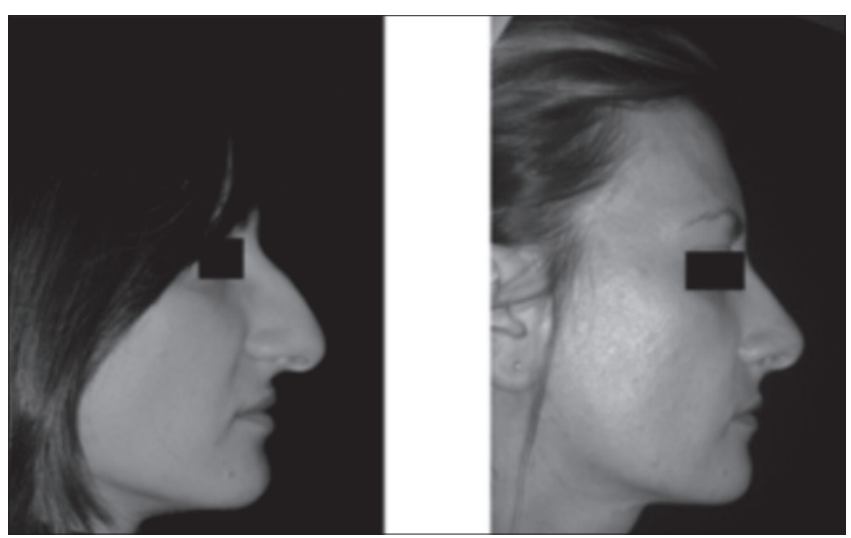

Fig. 5. Case \# 1, Pre- and post-operative pictures.

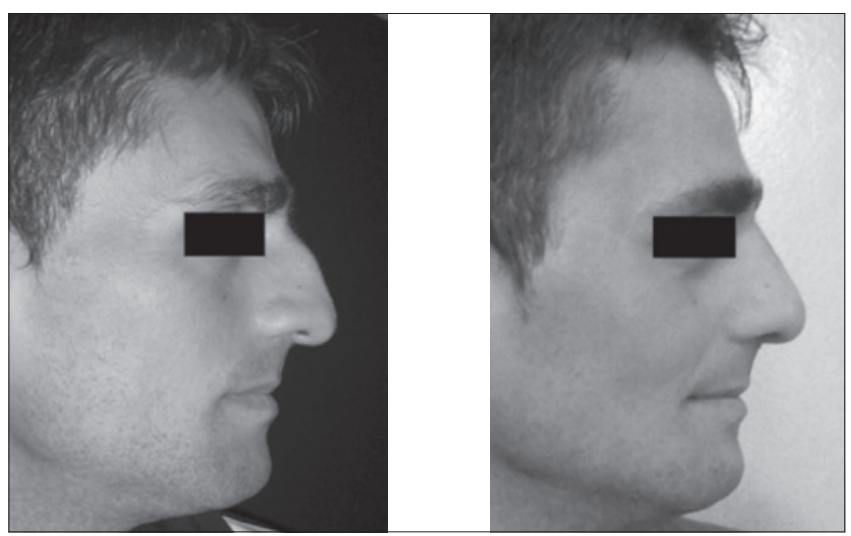

Fig. 6. The hump columellar strut: a reliable technique for correction of nasal tip underprojection.

tilages cephalic trimming procedures has been replaced by a cautious approach to the same. The reason for this lies on the experience that the mere resection of a prominent dome gives satisfactory immediate post-operative results for shape, rotation and definition, but under projection needs to be specific addressed.

The simplest way to eliminate under projection may be a Goldmann procedure, which combines dome division with medial crura suturing in higher position. Several pitfalls have been described in detail, the most important of which are the loss of tip projection and distortion. A possible alternative to the interrupted-strip procedures are inter/intradomal sutures to re-project the tip by dome re-positioning/re-orienting, but these techniques generally do not allow a major improvement and sometimes the result is temporary. Another option is the use of onlay grafts (Peck type) alone or combined with sutures to correct slight under projections or to camouflage irregularities. The safest way to achieve strong and durable tip support is with a columellar strut. This graft is effective 
to supplement the medial crura, which are the main pillar of the tripod structure of the tip ${ }^{20}$. All the described techniques useful in projection improvement can take advantage of the adjunctive and pivotal reinforcing effect of the columellar strut. Patients who have undergone previous trauma or rhinoplasty or submucous septal resection and those who require extensive onlay grafting may not have sufficient material for creating an adequate columellar strut. Alternative harvesting (e.g. ears or rib) mandates another operative site, lengthens surgery and increases morbidity. Alloplastic material is doomed by higher risks of infection/extrusion. Autologous local nasal bone like demucosalised inferior turbinate as a columellar strut shows good promise in terms of strength and persistence in time, but forced resection of the turbinates is demanded with potential for further complications such as bleeding, crusting, fracturing and increased surgical time ${ }^{21}$. The resected hump has been proposed as useful grafting material for closure of perforation and septal reconstruction and also for different reconstruction purposes of the nasal framework ${ }^{22}$. The use of hump columellar strut gives substantial advantages in rhinoplasty when hump removal is planned, no septal cartilage is sufficiently available and a tip projection improvement is needed. In these instances, the material is already present, its carving and shaping are easy and the quality of bone and cartilage are good. A further advantage in comparison with other grafting materials is the naturally straight and robust framework of this graft, and therefore very effective to support the tip overtime. No additional operative sites are needed. Placement requires little or no additional dissection. Long-term follow-up shows maintained projection. Packing is not mandatory since no turbinate resection is needed. Every other procedure can be utilised together with hump graft ${ }^{4-152326}$. Its disadvantages are the potential for intraoperative fracture and mild nasal tip stiffness similar to conventional strut or tongue-in-groove procedures.

\section{Conclusions}

In conclusion, the use of the resected nasal bone is a possible alternative autologous strut graft to increase and maintain nasal tip projection, the described procedure requires little and further surgical manouvers to be shaped and positioned without extra incision or donor site.

\section{References}

1 Fattahi T, Steinberg B, Fernandes R, et al. Repair of nasal complex fractures and the need for secondary septo-rhinoplasty. J Oral Maxillofac Surg 2006;64:1785-9.

2 Higuera S, Lee EI, Cole P, et al. Nasal trauma and the deviated nose. Plast Reconstr Surg 2007;120:64S-75S.
3 Emsen IM. A different approach to the reconstruction of the stubborn crooked nose with a different spreader graft: nasal bone grafts harvested from the removed nasal hump. Aesthetic Plast Surg 2008;32:266-73.

4 Boccieri A, Marano A. The conchal cartilage graft in nasal reconstruction. J Plast Reconstr Aesthet Surg 2007;60:188-94.

5 Sheen JH. Achieving more nasal tip projection by the use of a small autogenous vomer or septal cartilage graft: a preliminary report. Plast Reconstr Surg 1975;56:35-40.

6 Romo T III, Jablonski RD. Nasal reconstruction using split calvarial grafts. Otolaryngol Head Neck Surg 1992;107:622-30.

7 Kim DW, Shah AR, Toriumi DM. Concentric and eccentric carved costal cartilage: a comparison of warping. Arch Facial Plast Surg 2006;8:42-6.

8 Sarukawa S, Sugawara Y, Harii K. Cephalometric long-term follow-up of nasal augmentation using iliac bone graft. J Craniomaxillofac Surg 2004;32:233-5.

9 Daniel RK. Rhinoplasty and rib grafts: evolving a flexible technique. Plast Reconstr Surg 1994;94:597-611.

10 Pastorek NJ, Bustillo A, Murphy MR, et al. The extended columellar strut-tip graft. Arch Facial Plast Surg 2005;7:176-84.

11 Burm JS. Reconstruction of the nasal tip including the columella and soft triangle using a mastoid composite graft. J Plast Reconstr Aesthet Surg 2006;59:253-6.

12 Ham J, Miller PJ. Expanded polytetrafluoroethylene implants in rhinoplasty: literature review, operative techniques, and outcome. Facial Plast Surg 2003;19:331-9.

13 Lawson W, Reino AJ, Seidman D. The silicone columellar strut. Plast Reconstr Surg 1996;97:938-43.

14 Ahn J, Honrado C, Horn C. Combined silicone and cartilage implants: augmentation rhinoplasty in Asian patients. Arch Facial Plast Surg 2004;6:120-3.

15 Romo T III, Litner JA, Sclafani AP. Management of the severe bulbous nasal tip using porous polyethylene alloimplants. Facial Plast Surg 2003;19:341-8.

16 McGraw-Wall B. Facial analysis. In: Baily BJ, ed. Head and Neck Surgery-Otolaryngology. Philadelphia: Lippincott Williams \& Wilkins; 1993.

17 Alsarraf R. Outcomes research in facial plastic surgery: a review and new directions. Aesthetic Plast Surg 2008;121:251-7.

18 Janeke JB, Wright WK. Studies on the support of the nasal tip. Arch Otolaryngol 1971;93:458.

19 Adamson PA, Litner JA, Dahija R. The M-arch model. A new concept of nasal tip dynamics. Arch Facial Plast Surg 2006;8:16-25.

20 RW Westreich, W Lawson. The tripod theory of nasal tip support revisited. the cantilevered spring model. Arch Facial Plast Surg 2008;10:170-9.

21 Jones ME, RW Westreich, W Lawson. Augmentation of nasal tip projection using the inferior turbinate. review of tech- 
P.G. Giacomini et al.

nique and evaluation of long-term success. Arch Facial Plast Surg 2008;10:34-7.

22 Mocella S. Septal perforations' closure and reconstructive septorhinoplasty with hump and bioimplant material. In Annual Conferences of the EAFPS. Florence, Italy, 2005.

23 Krydel RWH, Konior RJ, Shumrick KA, et al. Advances in nasal tip surgery: the lateral crural steal. Arch Otolaryngol Head Neck Surg 1989;115:1206-12.
24 Vuyk HD. Suture tip plasty. Rhinology 1995;33:30-8.

25 Mocella S, Bianchi N. Double interdomal suture in nasal tip sculpturing. Facial Plast Surg 1997;13:179-96.

26 Toriumi DM, Tardy E. Cartilage suturing thecniques for correction of nasal tip deformities. Operat Thech in Otolaryngol Head Neck Surg 1995;6:265-73.

Received: March 26, 2016 - Accepted: November 20, 2016

Address for correspondence: Pier Giorgio Giacomini, Tor Vergata University School of Medicine and Surgery, Department of Surgery, U.O.C. Otorhinolaryngology, viale Oxford, 81, 00133 Rome, Italy. Fax + 3906 3243448. E-mail: pggiacomini@tiscali.it 